\title{
KARAKTER ANTROPOSENTRISME KAPITALIS TERHADAP ALAM DAN PEREMPUAN LEMBAH BALIEM
}

\author{
Rahmat Prayogi *) \\ rahmat.prayogi@fkip.unila.ac.id \\ rahmat.prayogi91@gmail.com
}

\begin{abstract}
This research was conducted to investigate capitalistic anthropocentrism towards nature and women in the novel Tanah Tabu. Freeport is an actor of capitalistic anthropocentrism while the Baliem Valley and the character of women in Tanah Tabu are representatives of the exploited objects. The analysis was carried out using the ecofeminism theory by Vandana Shiva. Therefore, the implication was to study the capitalistic anthropocentrism actions of Freeport which were examined based on the objectives of western colonialism (the United States) that came to Papua by developing the mining industry. The results of this study are first, the character of capitalistic anthropocentrism by Freeport is known from their motives in developing civilization with modern science, modernism towards conservatism, and colonialism. Second, ecofeminism places the character of Tanah Tabu women in role dualism; as victims and fighters against capitalistic anthropocentrism.
\end{abstract}

Keywords: anthropocentrism, capitalist, baliem, freeport

\section{PENDAHULUAN}

Novel Tanah Tabu, berkisah tentang epos perjuangan perempuan suku Dani dari pemiskinan dan penindasan perusahaan emas atau Freeport. Membaca Tanah Tabu samahalnya melihat perjuangan tokoh perempuan dari stigma suami serta budaya patriarkat suku Dani. Cerita Tanah Tabu tidak mengisahkan satupun tokoh laki-laki yang memihak perempuan. Seolah-olah pengarang dengan sengaja mengilustrasikan laki-laki sebagai sumber peperangan antarsuku, pelaku KDRT, dan oknum politik yang mayoritas militer. Adapun kehadiran dua tokoh berkelamin laki-laki yang memihak keluarga Mabel, yakni tokoh 'Pum' dan 'Kwee' yang diketahui di akhir cerita bersosok 'anjing tua' dan 'anak babi' . Keunikan lain dari novel Tanah Tabu adalah diceritakan melalui sudut pandang orang pertama 'aku', tetapi dituturkan dari penuturan tiga tokoh: Leksi, Pum dan Kwee saling bergantian mengungkap perjalanan hidup Mabel yang diketahui sebagai tokoh problematik. Tokoh problematik adalah tokoh yang berperan utama dalam menggerakkan konflik cerita. Karakter Mabel sebagai perempuan yang berani, pekerja keras, berwawasan modern serta 
toleran terkonstruksi dari kompleksitas segala persolan hidup yang dialami.

Perjuangan Mabel merupakan manifestasinya memeroleh hak kemakmuran hidup. Karena Mabel menyadari bahwa dirinya terkapitalisasi. Kesadaran Mabel menunjukkan posisinya yang lebih mengetahui cara memperlakukan dan mempertahankan hidup dari alam dibandingkan dengan kaum laki-laki. Adanya pertambangan Freeport, kehidupan Mabel semakin terpinggirkan dari alamnya. Freeport dalam proses pertambangan menempatkan antroposentrisme kapitalis sebagai fondasi. Perilaku antroposentris berusaha memutus dan memusnahkan relasi alam dengan perempuan, sehingga dampaknya menggerakkan kaum perempuan melakukan perlawanan. Menyikapi kenyataan itu, Mabel berusaha berada di garis depan dalam memperjuangkan kelestarian hutan, tumbuh-tumbuhan, tanah, dan air di Lembah Baliem yang menjadi sumber penghidupan.

Novel Tanah Tabu dikaji dengan teori ekofeminisme perspektif Vandana Shiva (1988:12), bahwa ketimpangan sosial yang terjadi dalam novel Tanah Tabu merupakan buah dari sebagian besar program dan proyek pembangunan yang melanggar integritas kaum perempuan sekaligus merusak produktivitas alam. Oleh karena itu, Shiva (1988:3) melalui ekofeminisnya menilai propaganda Barat dalam memproklamasikan gagasan 'pembangunan peradaban' telah menjadikan bangsa timur selayaknya lahan jajahan. Bangsa timur yang kental dengan kearifan tradisional dianggap barat sebagai bangsa yang tertinggal, sehingga proyek-proyek pembangunan yang berideologi kapitalisme dipilih sebagai alat dalam mencapai 'kemajuan' menurut model kemajuan barat. Akibatnya ketika itu kaum perempuan tidak lagi mampu memproduksi kehidupan, baik secara biologis dan sosial mereka dalam menyediakan kebutuhan hidup (Shiva, 1988:4). Apalagi barat juga mengkonsepsi gagasannya ke sebuah system yang disebut 'ilmu pengetahuan' dan kemudian disebarluaskan demi tercapainya afirmasi pelaksanaan proyek tersebut.

Apa yang diidentifikasi dan diklarifikasi Shiva melalui ekofeminisnya akan diaplikasikan ke dalam objek materi penelitian ini. Maka akan tampak karakter antroposentrisme kapitalis Freeport terhadap Lembah Baliem yang menyebabkan kehancuran tatanan alam Lembah Baliem dan ketimpangan hidup kaum perempuan suku Dani yang terefleksi dalam novel Tanah Tabu. Serta ekofeminisme akan memperlihatkan peran perempuan yang kedomestikannya lebih berdekatan dengan alam, selain diposisikan sebagai korban juga sekaligus perempuan 
diposisikan sebagai penyelamat dari dirinya dan masa depan ekosistem alam (dunianya).

\section{LANDASAN TEORI}

Menurut Shiva, manusia adalah pelaku utama punahnya ekosistem bumi. Nalar antroposentrisme dilanggengkan sebagai usahanya untuk mendayagunakan alam. Karena hasrat yang selalu tidak terpuaskan, manusia melalui akal pengetahuannya berusaha memenuhi hasratnya dengan berbagai gagasan yang mengindikasikan eksploitasi. Salah satunya menggagas industrialisasi dengan alasan demi memenuhi kebutuhan perkembangan zaman yang tidak lain merupakan konsep yang bersifat reduksionis. Hal ini yang mendasari pikiran Shiva bahwa reduksionisme merupakan wujud dasar penerapan ilmu pengetahuan modern dan develomentalis (pembangunan) yang menghadirkan kapitalisasi terhadap alam. Ia memercayai kedua aspek tersebut yang menyuburkan nalar antroposentrisme menjadi pilar utama pembangunan abad modern.

Berdasarkan pemaparan di atas dapat dirumuskan bahwa antroposentrisme terkonstruksi dari 'hasrat' manusia yang menginginkan 'kemakmuran', karena hasrat itu tidak mampu terpuaskan dari dirinya, manusia mencari cara untuk menjadikan SDA sebagai

'ladang' pemenuhan hasrat. Manusia disini dapat dilabelisasikan kepada bangsa barat, dimana bangsa yang selalu merasa haus akan memenuhi 'pembangunan peradaban'. Dalam memenuhi hasratnya, Barat menghadirkan ideologi antroposentris yang dikemas pada pembangunanpembangunan. Melalui ilmu pengetahuan modern, pembangunan digerakan dengan diberi nyawa kapitalis dan akal-akal maskulin. Sedangkan dunia ketiga yang memiliki kekayaan alam yang melimpah dan masih perawan menjadi daya tarik Barat untuk dieksploitasi.

Perilaku antroposentris tidak terlepas dari terjadinya transaksi terhadap alam yang dikomoditaskan. Alam menjadi bahan olah produksi suatu industri. Bagi Shiva (1988:9) kegiatan memproduksi barang sebagai kegiatan pokok ekonomi dianggap sama dengan pembangunan, kegiatan itu merusak potensi perempuan untuk menghasilkan penghidupan dan barang jasa untuk memenuhi kebutuhan pokok. Prosesproses produksi yang banyak menggunakan energy dan sumber daya yang lahir dari pertumbuhan ekonomi pasar ini menuntut pasokan sumber daya yang kian tinggi dari ekosistem. Terjadinya proses produksi terhadap alam kemudian disikapi sebagai adanya perilaku kapitalisme. Kapitalisme menempatkan alam sebagai objek yang 
ditransaksikan agar mendapatkan keuntungan. Pergerakan kapitalisme membaur kedalam proyek-proyek industri yang menggunakan sumber daya mengganggu proses-proses ekologi penting, karena industri seperti itu tidak saja menuntut pasokan bahan baku yang tinggi, tetapi juga mencemarkan udara, air dan tanah. Semakin terjadinya antroposentris yang mengakibatkan pencemaran semakin mengalami kehancuran masa depan ekosistem alam. Apalagi perilaku antroposentris didukung oleh ilmu pengetahuan yang tidak menghormati kebutuhan alam dan pembangunan yang tidak menghormati kebutuhan manusia yang kehidupannya berpangku pada alam.

Berdasarkan pemaparan di atas dapat disimpulkan kedalam beberapa asumsi dari konsep antroposentrisme kapitalis dalam memperlihatkan karakternya untuk mengeksploitasi alam dan menyingkiran kaum perempuan:

1. Antroposentrisme kapitalis: Karena hasrat yang selalu tidak terpuaskan, manusia melalui akal pengetahuannya berusaha memenuhi hasratnya dengan berbagai gagasan yang mengindikasikan eksploitasi kapitalis.

2. Karakter antroposentrisme kapitalis yakni opresif/eksploitatif, reduksionis, kuasa-menguasai (kolonialisme), berwawasan ilmu pengetahuan modern dan berteknologi.

3. Antroposentrisme kapitalis melihat alam sebagai objek, alat, komoditas, dan sarana bagi pemenuhan kebutuhan dan kepentingan manusia.

4. Antroposentrisme kapitalis hadir sebagai ideologi untuk menggerakkan kakitangan proyek-proyek pembangunan yang bermisikan 'pembangunan peradaban'.

5. Antroposentrisme berkonspirasi dengan ilmu pengetahuan modern: mengabaikan cara-cara pengetahuan ekologi dan pendekatan holistik, serta mengebirikan kaum perempuan sebagai ahli.

Sebuah kesadaran baru mulai muncul terkait mempersoalkan ilmu pengetahuan dan pembangunan yang menyingkap bahwa kedua aspek tersebut bukanlah kategori kemajuan yang universal, melainkan keduanya bagian dari proyek-proyek khusus yang tidak lain wujud dari patriarkat Barat modern. Shiva melihat hal ini sangat mengebirikan keberadaan kaum perempuan dunia ketiga. Bahkan Shiva (1988:34) menyatakan ilmu pengetahuan modern dan pembangunan adalah pernyataan paling brutal dan mutakhir dari ideologi patriarkat yang membawa kehancuran bagi alam dan seluruh umat manusia. Keduanya dalam praktiknya melanggengkan akar-akar 
ideologi dan bias revolusi ilmu pengetahuan dan revolusi industri, bahkan pengaruh keduanya meluas ke dalam bidang-bidang kegiatan baru dan daerah-daerah penindasan baru.

\section{METODE}

Penelitian ini merupakan penelitian kualitatif. Langkah pertama dalam penelitian ini adalah menentukan objek material dan objek formal. Adapun objek materialnya berupa novel Tanah Tabu karya Anindita S. Thayf. Sedangkan objek formal penelitian ini adalah teori ekofeminisme Vandana Shiva yang memperlihatkan perilaku antroposentrisme kapitalis: proyek pembangunan kapitalis dan opresi reduksionis ilmu pengetahuan modern.

Data dalam penelitian ini terbagi menjadi data primer dan sekunder. Data primer terdiri dari kata, frasa, dan kalimat yang dikutip dari novel Tanah Tabu (diterbitkan oleh PT Gramedia Pustaka Utama, Jakarta, Mei 2009; 237 halaman). Sedangkan data sekundernya berupa data lain yang diperoleh dari proses pembacaan jurnal, buku, koran, audio ataupun video yang memiliki relasi dengan data primer.

Metode pengumpulan data penelitian ini melalui teknik dokumentasi. Baik data terdokumentasi melalui novel, artikel jurnal, rekaman (audio), gambar (video), ataupun artikel-artikel dari internet. Dalam pengumpulan data, pertama-tama yang dilakukan adalah pembacaan dan pemahaman terhadap unsur cerita Tanah Tabu. Cerita yang merepresentasikan objek material yang akan digunakan untuk menjawab pertanyaan penelitian.

\section{HASIL DAN ANALISIS}

\section{a. Karakter Sosok Maskulin Tanah Tabu: Yang Memerkosa}

\section{1) Laki-laki Suku Dani: Berlindung dalam Kuasa Patrilineal}

Ketidakpihakan satupun tokoh lakilaki Tanah Tabu kepada kaum perempuan, mengindikasikan kelanggengan sistem patrilineal yang diteguhkan oleh laki-laki suku Dani. Sistem patrilineal yang dianut dalam kehidupan suku Dani menyebabkan kaum laki-laki selalu menganggap dirinya merasa (lebih) berkuasa di atas kaum perempuan. Dalam Tanah Tabu terefleksikan bahwa jikapun hidup kaum perempuan terkungkung dalam kekuasaan laki- laki, tetapi kehidupan perempuan Dani sebenarnya tidak mampu terlepas dari sosok laki-laki. Walaupun disadari kehadiran lakilaki dalam rumah tangga sebagai pelaku KDRT, sumber konflik peperangan antar suku, atau sumber pemiskinan keluarganya.

Dalam pandangan kaum perempuan, laki-laki suku Dani terlahir sebagai sosok pemberani, pandai berburu dan tidak gentar untuk berperang demi sukunya. Oleh sebab 
itu, bisa diperistri oleh laki-laki Dani apalagi yang kaya raya seolah-olah suatu keberuntungan atau menjadi impian yang menjamin masa depan seorang perempuan Dani. Entah itu sosok laki-laki berusia tua atau muda, hobi bermabuk-mabukan, ringan tangan kepada perempuan atau melakukan KDRT bahkan perempuan Dani rela dipoligami. Kemiskinan yang dialami perempuan suku Dani menempatkan harapan tersebut sebagai rapalan cita-cita yang tiada bosan diulang sampai harapan tersebut berubah menjadi nyata. Oleh karena itu , stigma yang ada dalam citra laki-laki suku Dani ditepis oleh harapan tersebut. Adapun stigma laki-laki suku Dani dapat diamati pada kutipan berikut.

"Laki-laki sombong yang merasa dirinya lebih berkuasa dan tinggi derajatnya dari perempuan. Dan termasuk pula sekelompok orang yang mengaku melindungi dan menghormati kaum perempuan, tapi sama sekali tidak pernah mau mendengar dan menghargai perbuatan, apalagi suara perempuan." (Thayf. 2009:170)

Perilaku laki-laki suku Dani yang selalu bertindak otoriter serta keras terhadap perempuan merupakan suatu konstruksi sosial budaya primitif yang sulit untuk diruntuhkan. Selama ajaran tradisi suku Dani masih diteguhkan dalam kehidupan bermasyarakat, patrilineal akan tetap langgeng dalam menempatkan kaum laki-laki sebagai penguasa dan perempuan sebagai budaknya. Oleh sebab itu, di- maklum apabila laki-laki suku Dani tidak memihak atau peduli terhadap kehidupan perempuan yang sebenarnya. Kenyataan yang ditemui dalam novel Tanah Tabu kehidupan perempuan suku Dani memiliki kehidupan yang menyinergi dengan alam Lembah Baliem. Akan tetapi, relasi tersebut tidak disadari atau diacuhkan oleh laki-laki suku Dani, sehingga dari keacuhan ini mengindikasikan adanya usaha subordinasi terhadap kebebasan perempuan suku Dani. Dengan sengaja laki-laki suku Dani membungkam ruang gerak perempuan agar posisi laki-laki berada pada pemegang kekuasaan atas segala kegiatan dan pengambilan keputusan kedomestikan perempuan.

Novel Tanah Tabu dalam persoalan ini memotret kaum perempuan suku Dani menjadi objek cerita yang dibalut dengan konflik kekerasan suku Dani dan berbagai bentuk penderitaan yang mereka alami. Apa yang terkisahkan dalam novel Tanah Tabu akan terlihat tidak sekedar fiktif belaka, apabila mengamati realitas yang ada di kehidupan suku Dani. Bagaimana melihat hasil survei dari berbagai LSM yang meneliti tingkat kekerasan perempuan Timika atau kabupaten suku Dani, menunjukkan adanya data yang memperlihatkan hampir setiap harinya kaum perempuan Timika mengalami KDRT akibat perilaku suaminya. Bahkan kenyataan lain yaitu 
posisi perempuan sebagai istri dituntut oleh suami atau adatnya menjadi tulang punggung keluarga. Beban ganda atas kehidupan yang dialami perempuan suku Dani menjadikan mereka sulit untuk memiliki kebebasan akan dirinya. Patrilineal laki-laki suku Dani menjadi ironis apabila melihat kembali konstruksi laki- laki suku Dani yang terlahir sebagai sosok yang memiliki keperkasaan atau keberanian dalam berperang. Keironisan yang dapat dicermati dalam citra laki-laki suku Dani dituturkan melalui dialog Mabel sebagai berikut.

"Kuakui kalau laki-laki kelahiran tanahku adalah para pemberani. Mereka tidak pernah gentar bertempur di medan perang dan berburu di hutan liar. Mereka adalah penakluk alam sejati. Namun yang sangat kusesali mengapa mereka membawa kebuasan itu sampai ke rumah? menjadikan para perempuan, istri sendiri, dan anak- anak sebagai korban. Sungguh tragis." (Thayf. 2009:66)

Dialog di atas merupakan interpretasi karakter Pace Mauwe yang dituturkan melalui ingatan Mabel ketika menanggapi persoalan rumah tangga yang dialami Mama Helda atau tetangganya. Pace Mauwe merupakan suami kedua Mabel. Mabel merupakan salah satu korban patriarkat laki-laki suku Dani. Bahkan Mabel menjanda dua kali, karena ia tidak terima atas perlakuan suami yang melakukan KDRT serta membelenggu dirinya dalam bayang-bayang sang suami.
Maka dari itu, Mabel memilih perceraian sebagai solusi untuk memerdekakan dirinya dari kuasa laki-laki. Jalan perceraian yang dipilih Mabel memperlihatkan usaha perlawanan Mabel dalam menentang patriarkat laki-laki Dani. Mabel berusaha melawan tradisi yang membelenggu kebebasan perempuan suku Dani. Walaupun kemudian Mabel hidup miskin tanpa kehadiran laki-laki, hal ini disadari Mabel sebagai pilihan yang tepat untuk memperoleh kebebasan.

\section{2) Freeport: Sosok Hantu yang Memerkosa}

Freeport merupakan pula sebagai sosok maskulin dalam Tanah Tabu. Pertama kalinya suku Dani bertemu orang Freeport berdatangan di Lembah Baliem yakni saat menjumpai rombongan Tuan Piet. Seketika itu suku Dani mengira Tuan Piet merupakan representasi sosok 'hantu'. Konsepsi sosok hantu dalam pandangan suku Dani terkonstruksi setelah menjumpai Tuan Piet dengan kondisi fisik bekulit putih, berambut pirang dan berpostur tubuh tinggi. Kondisi fisik yang khas orang barat tersebut, menjadi sosok yang lain dipandangan suku Dani yang berkulit hitam, berambut gimbal, bertubuh lebih pendek bahkan cuma mengenakan koteka. Kedatangan Tuan Piet di Lembah Baliem menandai mula dari perintisan Freeport untuk mendirikan industri pertambangan 
emas, perak dan tembaga di gunung Erstberg dan Grasberg. Disadari kemudian dalam pandangan Mabel, Freeport berkuasa di atas konservatisme masyarakat Lembah Baliem yang sangat meluhurkan warisan leluhurnya. Maka dari itu, adanya pertambangan Freeport samahalnya mendatangkan ancaman bagi kemakmuran suku Dani yang tinggal di Lembah Baliem. Pada kutipan berikut tampak konstruksi pertambangan Freeport di pandangan Mabel.

"Di tempat itulah aku pertama kali menyadari ada manusia-manusia tertentu yang sangat bernafsu menyaingi Tuhan. Mereka membuat sebuah dunia kecil tempat mereka sangat berkuasa. Kata-kata mereka adalah perintah. Senjata mereka adalah cambuk iblis sekaligus ciuman malaikat maut yang mampu membuatmu cacat seumur hidup atau bahkan kehilangan nyawa. Sedangkan seragam mereka adalah jubah samara yang sangat bagus untuk menyembunyikan kebusukan mereka. Kebusukan di balik kegagahan. Tempat itu betul-betul neraka dunia." (Thayf. 2009:160)

Berdasarkan kutipan di atas mengindikasikan bahwa selain laki-laki Dani, Freeport menjadi sosok maskulin dalam wujud lain dalam Tanah Tabu. Freeport merupakan sosok lain yang menjadi pelaku pemiskinan dan penindasan terhadap kehidupan suku Dani, terutama pemiskinan terhadap kaum perempuan dari kekayaan alam Lembah Baliem. Kekuasaan Freeport atas Lembah Baliem ditunjukkan dengan adanya konstruksi kemegahan wilayah pertambangan Freeport. Mabel menyikapi kemegahaan Freeport tidak lain wujud neraka dunia. Oleh sebab itu, Mabel menilai bahwa dari wilayah tersebut pula orang-orang Freeport bertindak selayaknya iblis yang mendatangkan petaka atau kematian bagi suku Dani. Kenyataan ini disadari Mabel setelah mengamati dan mengetahui sebab apa hidupnya terkungkung dalam kemiskinan dan terjerat dalam belenggu kebodohan.

Freeport yang bertindak sebagai pelaku antroposentrisme kapitalis berusaha mengeksploitasi SDA Lembah Baliem melalui pembangunan industri pertambangan yang berideologikan kapitalisme dan berpondasikan ilmu pengetahuan modern. Adapun perilaku eksploitasi tersebut merepresentasikan karakter antroposentrisme kapitalis Freeport yang diketahui berdasarkan motif 'pembangunan peradaban', motif modernisasi, dan motif konspirasi kolonialisme, sehingga motif tersebut mengakibatkan terjadinya pembangunan yang timpang di Lembah Baliem.

Berdasarkan motif-motif yang merepresentasikan karakter perilaku antroposentrisme kapitalis Freeport, maka dapat disimpulkan bahwa Freeport melalui industri pertambanggannya hanya mengedepankan imperialisme dan bersikap apatis terhadap kepunahan masa depan 
ekosistem Lembah Baliem. Kepunahan ekosistem yang terjadi menandai putusnya relasi alam dengan Mabel sebagai perempuan Dani yang bermata pencaharian hidup dari bertani dan berdagang sayuran yang diproduksi dari alam Lembah Baliem. Selain itu, antroposentrisme kapitalis Freeport berpengaruh pula pada kehancuran konservatisme suku Dani serta Freeport berusaha menyebarkan ideologi kapitalisme ke pranata kehidupan suku Dani.

\section{b. Dualisme Perempuan Tanah Tabu: Sebagai Korban dan Pelaku Perlawanan}

Akibat terjadinya antroposentrisme kapitalis terhadap alam Lembah Baliem mengakibatkan ekosistem alam tidak mampu berproduksi bagi kehidupan. Oleh karena persoalan tersebut, perempuan suku Dani diharuskan menanggung beban penderitaan yang paling parah dibandingkan kaum laki-laki. Perjuangan Mabel demi masa depan Leksi dapat dilihat pada kutipan novel berikut ini.

Karena itulah Mabel rela banting tulang bekerja apa saja untuk membiayai sekolah Leksi dan memenuhi semua kebutuhannya. Tentu saja, Mace juga ikut membantu: menggarap kebun sayur dan petatas milik Mabel sejak pagi hingga siang, lantas berjualan di pasar sampai sore pecah. Sedangkan Mabel berjualan kapur dan pinang yang dibuat dan dikumpulkannya sendiri, tetapi bukan dia yang mengambil pinang dari pohonnya, setelah sebelumnya membereskan pekerjaan rumah. (Thayf, 2009:63)

Dalam persoalan ini, ekofeminisme memperlihatkan posisi perempuan suku Dani sebagai korban yang tercermin dari kehidupan Mabel. Adapun fokus kajian ini dipusatkan pada problematik kehidupan Mabel yang diketahui sebagai tokoh problematik Tanah Tabu. Mabel sebagai korban karena kedomestikannya yang bergantung pada ekosistem Lembah Baliem. Oleh sebab itu, ketika Freeport mendirikan wilayah industri pertambangan dan mengantroposentri Lembah Baliem, kehidupan Mabel tidak mampu bersinergi dengan Lembah Baliem. Berikut kutipan yang mendukung.

Kampung Pace Mauwe digusur perusahaan emas milik pendatang dari lereng gunung tempat tinggal mereka sejak lama. Memang, ada kampung dan rumah baru yang diberikan sebagai gantinya di daerah bawah, tapi cukup jauh dari hutan, apalagi sungai. (Thayf. 2009:134)

Penderitaan Mabel mengakibat dirinya tidak mampu mereproduksi alam melalui pertanian dan tidak mampu menjadikan hasil pertanian sebagai komoditas perdagangan. Selain itu, Mabel dihadapkan dengan kenyataan rumah bangunan yang ia diami merupakan rumah sewa yang dibangun Freeport sebagai perumahan relokasi saat dirinya diusir dari kampung orangtuanya. Menyikapi persoalan ini, maka Mabel samahalnya 
bukan lagi sebagai pemilik tanah, tetapi ia sebagai penyewa tanah yang diwariskan dari leluhurnya.

Mabel sebagai pelaku perlawanan, dikarenakan keluhuran Mabel sebagai perempuan Dani yang selalu menjaga dan melestarikan amanah leluhur dalam wujud kekayaan SDA Lembah Baliem. Karena keluhuran tersebut, secara ekofeminis Mabel diposisikan sebagai perempuan yang masih memelihara prinsip feminis dan mendukung prinsip ekologis terhadap alamnya. Berikut kutipan yang mendukung.

Sebagai istri, Mabel tahu betul tugasnya dan senantiasa mengerjakan semuanya sebaik mungkin. Ia mengurus rumah, suaminya, Johanis, juga kebun-kebun mereka. Ia juga selalu menyempatkan diri membuat noken baru, menganyam keranjang, bahkan tak pernah membiarkan tempat sagu sampai kosong. (Thayf. 2009:134--135)

Pada kutipan berikut, "Semua orang tahu Mabel membenci perusahaan emas yang berkantor di ujung jalan besar sana. Ia sering berkomentar tajam dan pedas jika membicarakan perusahaan itu."2 Bukti adanya sikap Mabel yang memeliharadan mendukung prinsip feminine. Karena bagi Shiva tidak semua perempuan mendukung prinsip feminine. Setelah feminisme terkotak-kotak dalam pengaruh kekuasaan maskulinitas, banyak gerakan feminisme berjalan tidak seiring dengan esensi dari prinsip feminisme yang dipahami. Kebencian Mabel berlarut hingga pada sebuah gagasan besar yakni melakukan demo kepada Freeport. Berikut kutipan yang mendukung.

"Sudah kubilang dari kemarin-kemarin, lebih baik kita demo saja. Titik! Tidak usah ada pertemuan atau pembicaraan." (Thayf. 2009:172)

Oleh sebab itu, Mabel tampak lebih siap untuk membuka kembali kehidupan baru dari alam Lembah Baliem yang mengalami kepunahan, serta kesiapan Mabel mengindikasikan gerakan kesadaran atas penyebab kemiskinan dan pembodohan baik bagi dirinya ataupun suku Dani. Adapun perilaku perlawanan Mabel terinterpretasikan dalam upaya melakukan demo besar-besaran kepada Freeport yang disadari sebagai penyebab utama ketimpangan hidupnya. Perilaku perlawanan Mabel terhadap pembodohan dan pemiskinan, terinterpretasi dalam kegigihan Mabel untuk menyekolahkan putranya. Data di atas merupakan bukti adanya ketimpangan hidup yang dialami dan sikap pembangkang Mabel terhadap segala kebijakan yang ditetapkan Freeport. Selain itu, perlawanan Mabel terhadap kepunahan ekosistem Lembah Baliem terinterpretasi dalam upaya Mabel untuk mengolah lahan pertanian di tanah gambut serta upaya Mabel dalam menanamkan kembali benih tanaman seusai masa panen. 


\section{c. Alam Sebagaimana Perempuan Mengandung dan Melahirkan Kehidupan: Ekofeminisme Perempuan Tanah Tabu}

Alasan tokoh perempuan Tanah Tabu dihadirkan pengarang sebagai pelaku perlawanan antroposentrisme kapitalis Freeport diketahui karena relasi alam dan perempuan dalam perspektif ekofeminisme adalah alam sebagaimana perempuan yang mengandung dan melahirkan kehidupan. Oleh sebab itu, alasan kehadiran tokoh perempuan dapat dikaji berdasarkan perspektif ekofeminisme dalam melihat perempuan merupakan representasi 'ibu pertiwi', persoalan ini merupakan akibat konstruksi wacana yang dijadikan barat untuk mengeksploitasi SDA. Adapun perilaku Mabel menabukan Lembah Baliem samahalnya ia melindungi kesucian leluhur. Menabukan kesucian leluhur samahalnya Mabel menabukan diri sendiri. Perilaku menabukan ini menjadikan Lembah Baliem tetap perawan, sehingga jika terus terjaga keperawanannya maka kehidupan Mabel tidak akan menderita dari alamnya. Kemudian alasan lain yakni, perlawanan, interpretasi perempuan sebagai korban; kesadaran $\quad$ Mabel sebagai korbanantroposentris dan ketidakpihakan kaum laki-laki, menempatkan Mabel sebagai penyelamat atas dirinya sendiri. Perlawanan yang dilakukan Mabel samahalnya ia berusaha merintis gerakan kaum perempuan yang peduli terhadap kelestarian ekosistem serta kesiagannya dalam menciptakan kehidupan baru.

\section{Perempuan} mereproduksi kehidupan. Menjadi alasan lain dalam memposisikan Mabel sebagai pelaku perlawanan. Kekayaan SDA Lembah Baliem membuktikan bahwa Lembah Baliem memproduksi kehidupan bagi suku Dani. Profesi Mabel sebagai petani dan pedagang sayuran mengindikasikan kerja keras Mabel dalam mereproduksi kehidupan keluarga yang bersumber dari alam Lembah Baliem. Jadi antara Lembah Baliem dan Mabel terjalin mitra kerjasama dalam proses produksi-memproduksi kehidupan demi kemakmuran bersama. Adapun poin pembahasan, Keperempuanan: binatang piaraan selayaknya anak piara; kehadiran Pum dan Kwee merupakan sosok laki-laki heroik dalam keluarga Mabel. Padahal keduanya adalah sosok anjing tua dan anak babi. Keberpihakan Pum dan Kwee kepada keluarga Mabel mengindikasikan keduanya setia kepada yang memelihara mereka. Kemudian dikaji dari perspektif Mabel, hubungan keakraban Mabel yang hidup bertahun- tahun dengan Pum dan Kwee merepresentasikan perilaku ekofeminis dalam bentuk lain yang terbangun dari jiwa keperempuanan Mabel. 


\section{KESIMPULAN}

Antroposentrisme kapitalis terhadap alam dan tokoh perempuan dalam novel Tanah Tabu, mengakibatkan kehancuran tatanan alam Lembah Baliem dan ketimpangan hidup Mabel sebagai perempuan suku Dani yang kedomestikannya bergantung pada alam. antroposentrisme kapitalis yang diciptakan Freeport untuk mengambil alih kepemilikan SDA Lembah Baliem dari suku Dani sebagai ladang penjajahan. Antroposentrisme kapitalis dijalankan melalui industri pertambangan demi tuntutan pembangunan peradaban pendiri Freeport. Freeport sengaja menciptakan pembangunan yang berideologi kapitalisme, sehingga dampaknya menghancurkan sendi-sendi kehidupan suku Dani yang memegang teguh konservatisme.

Akibat terjadinya antroposentrisme kapitalis Freeport dalam hal ini ekofeminisme menempatkan kaum perempuan dalam dualisme peran, yakni perempuan suku Dani (Mabel) sebagai korban dikarenakan kedosmetikan yang bergantung pada alam Lembah Baliem. Lembah Baliem merupakan rumah; yang terdiri atas pekarangan, taman, sawah atau areal perkebunan. Tersingkirya Mabel dari alam akan mempermudah Freeport untuk mengeksploitasi SDA Lembah Baliem. Sedangkan Mabel diposisikan sebagai pelaku perlawanan, dikarenakan perempuan suku Dani yang masih tetap memelihara dan mendukung prinsip feminisme dan konservatisme terhadap leluhurnya. Oleh sebab itu, Mabel kelihatan lebih siap membuka dan menata ruang baru dibandingkan kaum laki-laki.

Kehadiran Mabel sebagai pelaku perlawanan dikarenakan entitas dirinya sebagai perempuan suku Dani yang meluhurkan alamnya sebagai wujud leluhur. Alam Lembah Baliem bagi Mabel adalah tabu atau dikeramatkan. Oleh karena itu, proses menabukan tersebut merepresentasikan diri Mabel tidak lain dari bagian tubuh alam Lembah Baliem. Adapun kesiagaan Mabel dalam memperjuangkan hidup dan alamnya mengindikasikan usahanya dalam menyinergikan prinsip feminis dengan prinsip ekologi. Prinsip feminis tersebut melahirkan gerakan kaum perempuan yang mengindikasikan naluri untuk empati, belas kasih, solidaritas, dan melestarikan ekosistem alam. 


\section{DAFTAR PUSTAKA}

Boserup, Ester. 1970. Women's Role in Economic Development. London: Allen and Unwin.

Candraningrum, Dewi. 2013. Ekofeminisme I: Dalam Tafsir Agama, Pendidikan, Ekonomi, dan Budaya. Yogyakarta: Jalasutra.

Iskandar, Johan. 2001. Manusia Budaya dan Lingkungan: Ekologi Manusia. Bandung: Humaniora Utama Press.

Keraf, A. Sonny. 2010. Etika Lingkungan Hidup. Jakarta: Penerbit Buku Kompas.

Mies, Maria. 1986. Patriarchy and Accumulation on a World Scale. London: Zed Books. Shiva, Vandana. 1988. Staying Alive: Women, Ecology and Survival in India. London: Zed Books.

Shiva, Vandana. 2005. Earth Democracy: Justice, Sustainability, and Peace. Cambridge: South End Press.

Thayf, Anindita S. 2009. Tanah Tabu. Jakarta: PT Gramedia Pustaka Utama. 